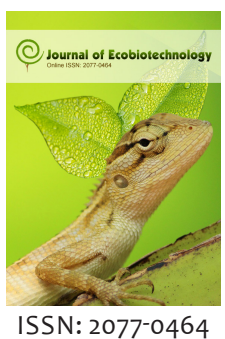

Received: April 30, 2020 Accepted: August 20, 2020 Published: September 03, 2020

*Corresponding Author: Mohammad Hasan Chowdhury

Email: mdhsnchowdhury@ gmail.com

\section{Prevalence of Staphylococcus aureus, Klebsiella spp., Escherichia coli and Pseudomonas spp. in some common Bangladeshi milk and dairy products}

\author{
Partha Paul', Md. Zahid Al Hasan', Arup Kumar², \\ Mohammad Hasan Chowdhury3*, Md. Jayed Chowdhury4, \\ Nafisa Habib Purba3, Moumita Chakma3, Shah Md. Ataur Rahman' \\ 'Department of Microbiology, Noakhali Science and Technology University, Sonapur, Noakhali-3814, Bangladesh, \\ ${ }^{2}$ Materials Science Division, Atomic Energy Centre, 4-Kazi Nazrul Islam Avenue, Shahbag, Dhaka-1000, Bangladesh, \\ ${ }^{3}$ Department of Food Technology and Nutrition Science, Noakhali Science and Technology University, Sonapur, \\ Noakhali-3814, Bangladesh, ${ }^{4}$ Faculty of Animal Science and Veterinary Medicine, Sher-e-Bangla Agricultural \\ University, Sher-e-Bangla Nagar, Dhaka-1207, Bangladesh
}

\begin{abstract}
The study was done to isolate Klebsiella spp., Staphylococcus aureus, Escherichia coli \& Pseudomonas spp. from raw milk, processed milk (powdered milk \& ultra-high-temperature milk) and dairy products (mango milk, and ice cream) During 3 months' time span of study, a total of ten samples were gathered where eight of the samples powdered milk (2), ultra-high-temperature milk (2), ice cream (2) \& mango milk (2) were gathered from different places of Bangladesh \& other 2 samples (raw milk) were collected from a cattle farm \& individual households in \& around Noakhali city. The samples were gathered under aseptic safety measures and were followed by plating on non-selective media (Nutrient broth) \& selective media (Mannitol Salt Agar \& Macconkey agar). The presumptive Klebsiella spp., Staphylococcus aureus, Escherichia coli \& Pseudomonas spp. isolates were identified by biochemical tests. Analysis of the result discovered that out of a total of 10 samples; raw milk (2), processed milk i.e. powdered milk (2), ultra-high-temperature milk (2) and dairy products i.e. mango milk (2) and ice cream (2) resulted in the isolation of 8 isolates (2.5\%) of S. aureus, (12.5\%) of Klebsiella spp., (2.5\%) of Pseudomonas spp. \& (2.5\%) of Escherichia coli. Results recommended a probability of potential public health threat of Staphylococcus aureus, Klebsiella spp., Escherichia coli \& Pseudomonas spp. resulting from contamination of milk and dairy products with pathogenic microorganisms is mainly due to unhygienic practices and conditions in the handling, production, and processing.
\end{abstract}

KEYWORDS: Raw milk, Escherichia coli, bacteria, Bangladesh

\section{INTRODUCTION}

Food-borne diseases (FBD) are characterized by the World Health Organization (WHO) as diseases of infectious or toxic nature brought about by or thought to be caused by the utilization of water or food. The pathogenesis of bacteria causing food-borne poisoning relies upon their capacity to produce toxins after ingestion (in the digestive tract) or intoxication (ingestion of preformed toxins in foodstuff) [1]. Among the bacteria predominantly engaged with these diseases, Staphylococcus aureus, Klebsiella spp., Escherichia coli \& Pseudomonas spp. are the main source of gastrointestinal infections resulting from the consumption of contaminated food.
Milk and dairy products are the prime habitats to complex microbial ecosystems; these are in charge of the wide varieties of taste, aroma, and texture of milk and dairy products. Contamination of milk and dairy products with pathogenic microorganisms is mainly due to handling, processing, and unhygienic condition. The presence of these pathogenic bacteria in milk and dairy products may pose a major health threat since the complex chemical composition and high nutritional content are hugely susceptible to a variety of microorganisms [2]. Many contaminants find their way to raw milk, from which they obtain access to dairy products $[3,4]$.

Staphylococcus aureus is extraordinarily adapted to cause infection in humans. Around $50 \%$ strain of this organism can

Copyright: $\odot$ The authors. This article is open access and licensed under the terms of the Creative Commons Attribution License (http://creativecommons.org/licenses/by/4.0/) which permits unrestricted, use, distribution and reproduction in any medium, or format for any purpose, even commercially provided the work is properly cited. Attribution - You must give appropriate credit, provide a link to the license, and indicate if changes were made. 
deliver enterotoxins related to food poisoning [5]. Disease through $S$. aureus run from minor skin infection such as boils, pimples, cellulitis, toxic shock syndrome, impetigo, and abscesses to life-endangering disease such as endocarditis, pneumonia, meningitis, and septicemia [2]. Gastroenteritis is self-limiting with the person getting better in eight to twentyfour hours. Side effects include vomiting, nausea, diarrhea, and abdominal pain [6]. Chapaval et al. seen the formation of staphylococcal enterotoxins in milk when milk was stored at $37^{\circ} \mathrm{C}$ to $42^{\circ} \mathrm{C}$ temperatures or when introduced to variations in temperature [7]. On heating at normal cooking temperature, the bacteria may be put to death but the toxins remain active [8]. Staphylococcal enterotoxins are exceedingly resistant and are believed to be more heat resistant in foodstuffs than in a laboratory culture medium [9]. Some virulent E. coli can even guide to urinary tract infections, diarrheal disease, neonatal meningitis, diarrheal disease, and gastroenteritis [10]. They harm the host in a few stages: colonizing the intestinal mucosal surface, evading the defenses by the host, and ultimately multiplying themselves in numbers [11]. Klebsiella is deft pathogens and can give rise to extreme illnesses, for example, pneumonia, septicemia, urinary tract infection (UTI), and soft tissue infection. The principal pathogenic reservoirs for transmission of Klebsiella are the gastrointestinal tract (GIT) and the hands of a dairyman. On account of their capacity to spread quickly in the cattle farm environment, these microscopic organisms tend to cause severe diseases [12]. Milkers' hands, a surface of cows' cooling tanks, teats, and teat cups are related to contamination of raw milk with Pseudomonas spp. on farms with manual and mechanical milking systems, showing that regardless of the kind of milking system and season, proper hygiene procedures of equipment, utensils, and workers' hands are essential to avoid contamination of milk and, accordingly, improve milk quality [13]. The most well-known pathogen in this genus is Pseudomonas aeruginosa which causes a wide range of diseases, from easy-to-cure serious infections of burn patients, ear infections, to severe lung infections which lead to significant difficulties in cystic fibrosis patients [14,15]. Besides Pseudomonas aeruginosa, other species e.g., Pseudomonas putida or Pseudomonas fluorescens is likewise a reason for infections in clinical settings $[16,17,18,19]$.

The objective of this research was to declare the occurrence of Staphylococcus aureus, Klebsiella spp., Escherichia coli \& Pseudomonas spp. in milk (raw milk, powdered milk \& ultra-hightemperature milk) and dairy products (mango milk, and ice cream).

\section{MATERIALS AND METHODS}

\section{Collection of Samples}

From October 2018 to December 2018, a total of 10 samples which includes raw milk (2 samples), powdered milk (2 samples), ultra-high-temperature milk (2 samples), mango milk (2 samples) and ice cream (2 samples) were collected from groceries, street-vendors, and supermarkets at different cities in Bangladesh. Only raw milk (2 samples) were collected from cattle farms \& individual households in \& around Noakhali city. The ice cream \& mango-milk samples were got as sold to the public in a cleaned and sanitized refrigerator or deep freezer while raw milk samples were got as sold in the containers available at cattle farms \& individual households. The samples were shifted as soon as possible to a laboratory of the Department of Microbiology, Noakhali Science \& Technology University, Sonapur, Noakhali with a minimum of delay to be examined.

\section{Isolation and Identification}

With slight modification isolation of $S$. aureus was attempted according to Ahaduzzaman et al. [20]. For the isolation of Staphylococcus aureus, $0.1 \mathrm{ml}$ of a sample was inoculated in plates containing Nutrient Agar and incubated overnight at $37^{\circ} \mathrm{C}$. Then sample from Nutrient Agar (HiMedia Pvt. Ltd.) was streaked on Mannitol Salt Agar (MSA) (HiMedia Pvt. Ltd.) and incubated for 24 hours at $37^{\circ} \mathrm{C}$. Bacterial growth was observed after overnight incubation and the selection of positive samples colony was carried out based on the morphology of the colony and confirmed by Gram's staining.

With slight modification isolation of E.coli was attempted according to Cheesbrough [21]. For the isolation of E. coli, $0.1 \mathrm{ml}$ of all the samples were cultured primarily in Nutrient Agar (HiMedia Pvt. Ltd.) at $37^{\circ} \mathrm{C}$ for $18-24$ hours, then subcultured onto the MacConkey Agar (HiMedia Pvt. Ltd.) by streak-plating technique and incubated at $37^{\circ} \mathrm{C}$ overnight. Bacterial growth was observed after overnight incubation and the selection of positive samples colony was carried out based on the morphology of the colony and confirmed by Gram's staining.

With slight modification isolation of Pseudomonas spp. was attempted according to Priyadharsini et al. [22]. For the isolation of Pseudomonas spp., 0.1 sample was streaked on to Nutrient Agar (HiMedia Pvt. Ltd.) and MacConkey Agar (HiMedia Pvt. Ltd.) plate and incubated at $37^{\circ} \mathrm{C}$ for 24 hours. Next day individual colonies were selected and identified based on morphological, cultural, and biochemical characteristics.

With slight modification isolation of Klebsiella spp. was attempted according to Bruce et al. [23]. For the isolation of Klebsiella spp., 0.1 sample was streaked on to Nutrient Agar (HiMedia Pvt. Ltd.) and Mac Conkey Agar (HiMedia Pvt. Ltd.) plate and incubated at $37^{\circ} \mathrm{C}$ for 24 hours. Next day individual colonies were selected and identified based on morphological, cultural, and biochemical characteristics.

\section{Morphological Characteristics}

The smear was formulated from the isolated culture on a clean grease-free microscopic glass slide and stained with Gram's Method of staining. The stained smear was then observed under a microscope. Smear stated both Gram-positive \& GramNegative, spherical cells arranged in irregular clusters resembling a bunch of grapes for Staphylococcus aureus; spherical cells arranged singly, in pairs, or short chains and sometimes in clusters for Klebsiella spp. \& spherical cells arranged singly or in pairs for Pseudomonas spp. \& Escherichia coli (Table 1). 


\section{Biochemical Examination}

Biochemical tests were performed to confirm Staphylococcus aureus, Klebsiella spp., Escherichia coli \& Pseudomonas spp. using Catalase test, Oxidase test, Motility Indole Urease (MIU) test, IMViC tests, Nitrate test, Triple Sugar Iron (TSI) test \& Carbohydrates tested include glucose, lactose, maltose, mannitol, sucrose, and xylose.

\section{RESULTS \& DISCUSSION}

Analysis of the result showed that out of a total of 10 samples; raw milk (2), processed milk i.e. powdered milk (2), Ultra HighTemperature milk (2) and dairy products i.e. mango milk (2), ice cream (2) resulted in the isolation of 8 isolates $(2.5 \%)$ of S. aureus, $(2.5 \%)$ of Klebsiella spp., (12.5\%) of Pseudomonas spp. \& $(2.5 \%)$ of Escherichia coli.

The biochemical identification of S. aureus, Klebsiella spp., Pseudomonas spp. \& Escherichia coli were conducted by performing the biochemical test. The biochemical test was conducted as stated on Bargen's manual of Determination Bacteriology. In this project, 16 biochemical tests have been done. Based on the result both the major gram-negative \& positive pathogenic bacteria have been identified (Table 2).

\section{Staphylococcus Aureus}

Staphylococcus aureus could be isolated with percentages of 2.5 from investigated mango milk samples (Table 3).
The presence of $S$. aureus in mango milk may derive from mouth, skin, or nose of workers while handling the food in the processing plant. S. Aureus is a good personal hygienic indicator of staff with respiratory suppuration and infection [24]. Staphylococcus aureus is one of the key etiological agents of bovine mastitis and a high percentage of food handlers performing in dairy distribution is a nasal carrier of S. aureus [25]. The growth of S.aureus in food products is a prospective public health hazard since many strains can generate thermostable enterotoxins which can originate food poisoning if ingested as well as enterotoxins that perform on vomiting center in the brain via the vagus nerve [26].

\section{Escherichia Coli}

Data recorded in (Table 3) revealed that the prevalence of Escherichia coli was 2.5\%; from examined raw milk samples.

The public health hazard of E.coli organism has been focused by several researchers as they have been implicated in human cases of epidemic diarrhea in infants, sporadic diarrhea, gastroenteritis in children as well as food poisoning $[27,28]$. The high prevalence of different organisms in the inspected samples may be due to the lack of cleanliness in handling, manufacturing, and distribution and ignorance of sanitary measures during storage. On the other hand, it is predicted that the storage temperature would influence the contamination of the imported samples.

\section{Pseudomonas spp.}

Data recorded in (Table 3) revealed that the prevalence of Pseudomonas spp. was $2.5 \%$ from examined ice cream.

Table 1: Morphological and culture characteristics of Staphylococcus aureus, Klebsiella spp., Escherichia coli and Pseudomonas spp.

\begin{tabular}{lll}
\hline Isolated bacteria & Gram staining & Culture characteristics on selective media \\
\hline Staphylococcus aureus & Gram positive cocci (in clusters) & MSA: Yellow colonies; may have yellow halo around colonies. \\
Klebsiella spp. & Gram negative (in short chains) & MAC: Appears pink, large, glistening and mucoid. \\
Escherichia coli & Gram negative (singly) & MAC: Bright pink or red, flat, convex, dry. \\
Pseudomonas spp. & Gram negative (singly) & MAC: Colorless, flat, smooth, non-lactose fermenting colonies with regular margin. \\
\hline
\end{tabular}

Table 2: Biochemical tests for the identification of microbial isolates

\begin{tabular}{|c|c|c|c|c|c|}
\hline Biochemical test & & Escherichia coli & Pseudomonas spp. & Staphylococcus aureus & Klebsiella spp. \\
\hline Catalase & & + & + & + & + \\
\hline Citrate & & - & + & - & + \\
\hline Motility & & + & - & - & - \\
\hline Indole & & + & - & - & - \\
\hline Urease & & - & - & - & - \\
\hline Oxidase & & - & + & - & - \\
\hline \multirow[t]{4}{*}{ Triple sugar iron } & Slant & $A$ & $\mathrm{~K}$ & - & $A$ \\
\hline & Butt & $A$ & K & - & $A$ \\
\hline & Gas & + & - & - & + \\
\hline & $\mathrm{H}_{2} \mathrm{~S}$ & - & - & - & - \\
\hline MR & & + & - & + & - \\
\hline VP & & - & - & + & + \\
\hline Glucose & & $A G$ & $A$ & $A$ & $A G$ \\
\hline Lactose & & $A G$ & - & $A$ & $A G$ \\
\hline Xylose & & A & - & - & - \\
\hline Mannitol & & $A G$ & - & $A$ & $A G$ \\
\hline Maltose & & - & - & $A$ & - \\
\hline Sucrose & & - & - & $A$ & $A G$ \\
\hline Nitrate & & + & + & + & + \\
\hline
\end{tabular}

$+=$ positive; - = negative; $A=$ Acid; $G=G$ as; $K=$ Alkaline. 
Table 3: Incidence of some food poisoning microorganisms in the examined samples

\begin{tabular}{|c|c|c|c|c|c|c|c|c|c|}
\hline & \multirow[t]{2}{*}{ No. of Samples } & \multicolumn{2}{|c|}{ Escherichia coli } & \multicolumn{2}{|c|}{ Pseudomonas spp. } & \multicolumn{2}{|c|}{ Staphylococcus aureus } & \multicolumn{2}{|c|}{ Klebsiella spp. } \\
\hline & & No. of isolate (s) & Prevalence & No. of isolate (s) & Prevalence & No. of isolate (s) & Prevalence & No. of isolate (s) & Prevalence \\
\hline Raw milk & 2 & 1 & $2.5 \%$ & - & 0 & - & 0 & 1 & $2.5 \%$ \\
\hline Powdered milk & 2 & - & 0 & - & 0 & - & 0 & 2 & $5 \%$ \\
\hline UHT milk & 2 & - & 0 & - & 0 & - & 0 & - & 0 \\
\hline Ice cream & 2 & - & 0 & 1 & $2.5 \%$ & - & 0 & 2 & $5 \%$ \\
\hline Mango milk & 2 & - & 0 & - & 0 & 1 & $2.5 \%$ & - & 0 \\
\hline
\end{tabular}

As shown by da Silva et al. [29] when considering Pseudomonas spp., milkers' hands are one of the primary sources of milk contamination in properties with manual milking.

Total counts of Pseudomonas spp. can be decreased by choosing proper hygiene practices during the milking operation and storage of refrigerated raw milk [29,30]. Since Pseudomonas spp. can even influence the processing of ultra-high temperature treated dairy products [31,32], good hygienic practices can contribute to the quality of dairy products and in industrial productivity. To decrease the count of Pseudomonas spp. in milk, utensils \& milking equipment ought to be cleaned with water of good quality, and disinfected immediately after use [33]. Production of glycosidase, lipase, phospholipase $\mathrm{C}$, and proteinase enzymes in milk strongly damaged the milk fat protein-membrane causing milk rancid, fruity, bitter, off-flavor, and putrid which particularly due to the growth of these organisms in raw milk [34]. Other spoilage defects include slime and pigment production [35]. These unwanted changes render milk of inferior quality and unfit for human consumption or it may possess public health hazards [36,37]. Careful sanitary procedures coupled with the application of hazard analysis of critical control point (HACCP) programs among dairy farms during the production of milk as well as good personal hygiene should be adopted for enhancing its microbial safety.

\section{Klebsiella spp.}

Klebsiella spp. could be isolated with percentages of 2.5, 5.0, and 5.0 from examined raw milk, powdered milk \& ice cream samples, respectively (Table 3 ).

Klebsiella spp. are commonly present in the soil, water rumen content, troughs, bedding, feces, holding pens \& alleyways on dairy farms [38].

Existence of Klebsiella spp. throughout the dairy farm environment could be expected based on its frequent existence in feces $[39,40]$, but participating farmers did not know about this. Fecal contamination of the udder, which may be caused by cow traffic via dirty alleyways and holding pens, is connected with an additional risk of the presence of Klebsiella spp. on teat skin during and before milking [41]. Meanwhile, hygiene of holding pens \& alleyways should be allowed as an important feature of preventing mastitis due to Klebsiella spp.

\section{CONCLUSION}

Food poisoning due to Pseudomonas spp., S. aureus, Klebsiella spp., \& Escherichia coli is of main concern in public health programs worldwide. Pseudomonas spp., S. aureus, Klebsiella spp., \& Escherichia coli may be available in milk and milk products as a result of milk gathered from the animal suffering from disease condition and excreting in milk or due to unhygienic conditions during processing, production, handling $\&$ storage of milk products, which are the major causes of foodborne diseases. Results undoubtedly indicated that raw milk, processed milk (powdered milk \& Ultra High-Temperature milk) and dairy products (mango milk, and ice cream) present in the market were contaminated with Pseudomonas spp., S. aureus, Klebsiella spp., Escherichia coli \& Klebsiella spp. posing a high risk of food poisoning. Thus more hygienic preventive practices are required to decrease bacterial contamination, to increase the wholesomeness of these milk and dairy products.

\section{AUTHORS' CONTRIBUTIONS}

P.P., M.Z.A.H., A.K., M.H.C., M.J.C., N.H.P., M.C., and S.M.A.R. conceived, designed, and performed the experiments. M.H.C., and M.J.C. drafted the manuscript. All authors read and approved the final manuscript.

\section{ACKNOWLEDGMENTS}

Authors are grateful to the Department of Microbiology, Noakhali Science \& Technology University, Noakhali, Bangladesh, for providing financial support to the present investigation.

\section{COMPETING INTERESTS}

The authors declare that they have no competing interests.

\section{REFERENCES}

1. Le Loir Y, Baron F, Gautier M: Staphylococcus aureus and food poisoning. Genet Mol Res 2003;2:63-76.

2. Soomro AH, Arain MA, Khashkeli M, Bhutto B, Memon AQ: Isolation of Staphylococcus aureus from milk products sold at sweet meat shops of Hyderabad. On Line J of Bio Sci 2003;3:91-94.

3. Al Khatib IA, Al Mitwalli SM: Microbiological quality and sample collection policy for dairy products in Ramallah and Al-Bireh district, Palestine. East Mediterr Health J 2009; 15:709-716.

4. Sadek ZI, Hosny IM, El-Kholy WI, El-Dairouty RK: Comparative investigations for detection of foodborne microorganisms in Egyptian hard cheese "Ras" using conventional and fast biochemical tests. Global Veterinaria 2009;3:189-195.

5. Payne DN, Wood JM: The incidence of enterotoxin production in strains of Staphylococcus aureus isolated from foods. J Appl Bacteriol 1974; 37:319-325.

6. Adams MR, Moss MO: Food microbiology, $2^{\text {nd }}$ Ed. Royal Society of Chemistry 2000 
7. Chapaval L, Moon DH, Gomes JE, Duarte FR, Tsai SM, Nassu RT: Efeito da temperatura sobre a produção de enterotoxina estafilocócica em leite. Hig alim 2010;162-167.

8. Presscott LM, Harley JP, Klein DA: Text book of Microbiology. Brown Publishers 2002;5:441-442.

9. Bergdoll MS: Enterotoxins. In: Staphylococci and Staphyloococcal Infections (Easman CSF, Adlam C, eds.). Academic Press, London, UK 1983;2:559-598

10. Barrett $C L$, Herring $C D$, Reed JL, Palsson BO: The global transcriptional regulatory network for metabolism in Escherichia coli exhibits few dominant functional states. Proc Natl Acad Sci 2005; 102:19103-19108.

11. Nataro JP, Kaper JB: Diarrheagenic Escherichia coli. Clin Microbiol Rev 1998; 11:142-201

12. Podschun R, Ullmann U: Klebsiella spp. as nosocomial pathogens: epidemiology, taxonomy, typing methods, and pathogenicity factors. Clin Microbiol Rev 1998;11:589-603.

13. Vidal A, Saran Netto A, Vaz AC, Capodifóglio E, Gonçalves A, Rossi GA, Figueiredo AS, Ruiz VL: Pseudomonas spp. : contamination sources in bulk tanks of dairy farms. Pesquisa Veterinária Brasileira 2017;37:941-948

14. Barbier F, Wolff M: Multi-drug resistant Pseudomonas aeruginosa: towards a therapeutic dead end? Med Sci (Paris) 2010;26:960-968 [in French].

15. Azzopardi EA, Azzopardi E, Camilleri L, Villapalos J, Boyce DE, Dziewulski P, Dickson WA, Whitaker IS: Gram negative wound infection in hospitalised adult burn patients-systematic review and metanalysis. PLoS One 2014;9:e95042.

16. Gilarranz R, Juan C, Castillo-Vera J, Chamizo FJ, Artiles F, Alamo I, Oliver A: First detection in E urope of the metallo- $\beta$-lactamase IMP15 in clinical strains of Pseudomonas putida and Pseudomonas aeruginosa. Clin Microbiol Infect 2013;19:E424-E427.

17. Erol S, Zenciroğlu A, Dilli D, Okumus N, Aydin M, Göl N, Erdem F Tanir G: Evaluation of nosocomial blood stream infections caused by Pseudomonas species in newborns. Clin Lab 2014;60:615-620.

18. Bhattacharya D, Dey S, Kadam S, Kalal S, Jali S, Koley H, Sinha R, Nag D, Kholkute SD, Roy S: Isolation of NDM-1-producing multidrugresistant Pseudomonas putida from a paediatric case of acute gastroenteritis, India. New Microbes New Infect 2015;5:5-9.

19. Mazurier S, Merieau A, Bergeau D, Decoin V, Sperandio D, Crépin A, Barbey C, Jeannot K, Vicré-Gibouin M, Plésiat P, Lemanceau P: Type III secretion system and virulence markers highlight similarities and differences between human-and plant-associated pseudomonads related to Pseudomonas fluorescens and P. putida. Appl. Environ. Microbiol. 2015;81:2579-2590.

20. Ahaduzzaman M, Hassan MM, Alam M, Islam SK, Uddin I: Antimicrobial resistance pattern against Staphylococcus aureus in environmental effluents. Res J Vet Pract 2014;2:13-16.

21. Cheesbrough M: Medical laboratory manual for tropical countries. Tropical Health Technology Ltd, Doddington, Cambridgeshire, 1984: Vol 2.

22. Priyadharsini M, Bhardwaj S, Sheeba E: Isolation, identification of microbial isolates from urinary tract infection patients and evaluation of antimicrobial activity using plant extracts. Int J Curr Microbial Appl
Sci 2014;3:153-160

23. Bruce SK, Schick DG, Tanaka L, Jimenez EM, Montgomerie JZ: Selective medium for isolation of Klebsiella pneumoniae. J Clin Microbiol 1981:13:1114-1116.

24. Kamat MY, Sulebele G and Nirupama S: A comparative evaluation of media enumeration of enterotoxigenic Staphylococci by selective enrichment technique. J Food Sci Technol 1991;28:381-373.

25. Garcia ML, Francisco JJ, Moreno B: Nasal carriage of Staphylococcus species by food handlers. Int J Food Microbiol 1986;3:99-108.

26. Erkmen, O: Behavior of Staphylococcus aureus in Turkish Feta cheese during manufacture and ripening. J Food Protect 1995;58:1201-1205.

27. Cohen AE, Kerdahi KF: Evaluation of a rapid and automated enzymelinked fluorescent immunoassay for detecting Escherichia coli serogroup 0157 in cheese. J AOAC Int 1996;79:858-860.

28. Vernozy-Rozand C: Detection of Escherichia coli 0157 and other verotoxin producing E.coli (VTEC) in food. J Appl Microbial 1997:82:537-557.

29. da Silva LCC, Beloti V, Tamanini R, d'Ovidio L, de Mattos MR, de Arruda AMCT, Pires EMF: Tracking sources of microbiologic contamination of raw milk during milking process in dairy farms from Agreste of Pernambuco. Semina: Ciências Agrárias 2011;32:267-276.

30. Fagundes CM, Fischer V, Silva WPD, Carbonera N, Araújo MR Presence of Pseudomonas $s p p$ in milking phases with different hygienic handling procedures and in refrigerated Milk. Ciência Rural 2006;36:568-572.

31. Chen TR, Wei QK, Chen YJ: Pseudomonas spp. and Hafnia alve growth in UHT milk at cold storage. Food Control 2011;22:697-701.

32. Baglinière F, Tanguy G, Jardin J, Matéos A, Briard V, Rousseau F Robert B, Beaucher E, Humbert G, Dary A, Gaillard JL: Quantitative and qualitative variability of the caseinolytic potential of different strains of Pseudomonas fluorescens: Implications for the stability of casein micelles of UHT milks during their storage. Food Chem 2012;135:2593-2603.

33. Codex Alimentarius Commission. General requirements (Food Hygiene). Joint FAOMHO Food Standards Programme. Food and Agriculture Organization of the United Nations, Rome, 1997:Vol.1B (Suppl.).

34. Bassette R, Fung DY, Mantha VR, Marth EH: Off-flavors in milk. Crit Rev Food Sci Nutr 1986; 24:1-52

35. Walker SJ: Major spoilage micro-organisms in milk and dairy products. Int J Dairy Tech 1988;41:91-92.

36. Foster EM: Dairy microbiology. Ridgeview Pub Co 1983.

37. Kraft AA: Psychotropic Bacteria in FoodsDisease and Spoilage. CRC Press 1992.

38. Zadoks RN, Griffiths HM, Munoz MA, Ahlstrom C, Bennett GJ, Thomas E, Schukken YH: Sources of Klebsiella and Raoultella species on dairy farms be careful where you walk. J Dairy Sci 2011;94:1045-1051.

39. Munoz MA, Ahlström C, Rauch BJ, Zadoks RN: Fecal shedding of Klebsiella pneumoniae by dairy cows. J Dairy Sci 2006;89:3425-3430.

40. Munoz MA, Zadoks RN: Patterns of fecal shedding of Klebsiella by dairy cows. J Dairy Sci 2007;90:1220-1224.

41. Munoz MA, Bennett GJ, Ahlström C, Griffiths HM, Schukken YH, Zadoks RN: Cleanliness scores as indicator of Klebsiella exposure in dairy cows. J Dairy Sci 2008;91:3908-39 